\title{
Meiotic recombination within plant centromeres
}

\author{
Joiselle B. Fernandes, Piotr Wlodzimierz and Ian R. Henderson \\ Department of Plant Sciences, University of Cambridge, Cambridge, United Kingdom \\ Correspondence: irh25@cam.ac.uk
}

\begin{abstract}
Meiosis is a conserved eukaryotic cell division that increases genetic diversity in sexual populations. During meiosis homologous chromosomes pair and undergo recombination that can result in reciprocal genetic exchange, termed crossover. The frequency of crossover is highly variable along chromosomes, with hot spots and cold spots. For example, the centromeres that contain the kinetochore, which attach chromosomes to the microtubular spindle, are crossover cold spots. Plant centromeres typically consist of large tandemly repeated arrays of satellite sequences and retrotransposons, a subset of which assemble CENH3-variant nucleosomes, which bind to kinetochore proteins. Although crossovers are suppressed in centromeres, there is abundant evidence for gene conversion and homologous recombination between repeats, which plays a role in satellite array change. We review the evidence for recombination within plant centromeres and the implications for satellite sequence evolution. We speculate on the genetic and epigenetic features of centromeres that may influence meiotic recombination in these regions. We also highlight unresolved questions relating to centromere function and sequence change and how the advent of new technologies promises to provide insights.
\end{abstract}

Keywords: Meiosis, centromeres, recombination, DSB, crossover, CENH3, H3K9me2, DNA methylation, satellites.

\section{Main text:}

\section{Meiosis, centromeres and recombination:}

Meiosis is a specialized eukaryotic cell division that produces haploid cells, via one round of DNA replication and two rounds of chromosome segregation [1]. Following chromosome replication, sister chromatids are held together by cohesin rings [2]. Unlike during mitosis, meiotic homologous chromosomes pair and synapse to form bivalents (Fig. 1A) [1]. During meiotic prophase I chromosomes undergo DNA double strand breaks (DSBs) that may be repaired using a homolog to form reciprocal crossovers [1,3]. At the end of the first meiotic division, homologous chromosomes segregate, which is achieved by mono-orientation of sister chromatid kinetochores towards the same cell pole (Fig. 1A) [4,5]. Crossovers form a physical link (chiasmata) between the homologs, which together with sister cohesion, are required for balanced segregation [1]. Cohesin is lost from the chromosome arms at the end of meiosis I, but is protected at the centromeres, until it is lost during meiosis II, allowing sister chromatids to segregate into haploid daughter cells [1]. Hence, meiosis involves specialized regulation of chromosome cohesion, interhomolog recombination and centromere behavior in order to produce genetically diverse haploid daughter cells.

Meiotic DSBs form in plants via a conserved SP011-1/SPO11-2/MTOPVIB topoisomerase-like complex $\left[6^{*}, 7^{*}\right]$. SPO11 proteins become covalently bound to DSB 5'-ends during catalysis [8]. 
Endonuclease followed by exonuclease activities remove SPO11 and initiate resection to produce 3'-overhanging single stranded DNA (ssDNA) [9]. Meiotic ssDNA is bound by the RecA homologs RAD51 and DMC1, which promotes strand invasion of a sister chromatid or a homologous chromosome $[1,9]$. Interhomolog joint molecules form via displacement loops (Dloops), following which the invading 3 '-end may undergo template driven synthesis $[1,3]$. At this stage extended D-loops may be dissolved by anti-crossover activities and the ssDNA can return to its parent chromosome and be repaired as a non-crossover $[1,3]$. Hence, template-synthesis over polymorphic sites can cause gene conversion and 3:1 inheritance through meiosis [1]. In Arabidopsis, $\sim 100-200$ DSB-associated foci are cytologically observed along the chromosome axis during early prophase I, whereas only 10 DSBs mature into crossovers [1,6*]. The repair of the remaining DSBs occurs either via the non-crossover pathway, or using a sister chromatid [1]. Measurement of meiotic gene conversion using transgenes or sequencing of recombinant Arabidopsis plants has defined rates in the range of $1.1-8.8 \times 10^{-5}$ sites per meiosis [10-12]. Evidence for intersister repair comes from analysis of haploid meiosis, where recombination is RAD51 and REC8 dependent, but DMC1 independent [13].

In plants, the conserved Class I 'ZMM' pathway provides the major activity for crossover formation [1]. This pathway acts to stabilize interhomolog joint molecules and promote crossover resolution of double Holliday junction $(\mathrm{dHJ})$ intermediates [1,3]. Within plants, the ZMM pathway includes the MER3 helicase, HEI10 E3 ligase, ZIP4, SHORTAGE IN

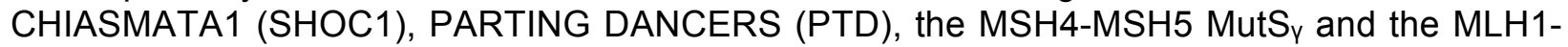
MLH3 MutL $L_{Y}$ heterodimers [1]. A minority of crossovers are formed by the Class II pathway(s), that involve structure specific endonucleases, including MUS81 [1]. A key distinction between Class I and II crossovers, is that the former show interference, meaning that crossovers are more widely spaced than expected by chance [1]. In Arabidopsis, acting in opposition to these pro-crossover activities are partially redundant anti-crossover pathways, including (i) FANCM, MHF1 and MHF2, (ii) FIDGETIN-LIKE-1 (FIGL1) and FIGL1 INTERACTING PROTEIN (FLIP) and (iii) RECQ4A, RECQ4B, RMI1 and TOPOISOMERASE3a, which act to disassemble joint molecules or by regulating strand invasion [1,14]. In plants the combined outcome of the competing pro- and anti-crossover pathways is that most chromosomes experience between 13 crossovers, irrespective of genome size, and in divergent positions between independent meioses.

Meiotic DSB and crossover frequency tend to be non-homogenously distributed along chromosomes, with narrow kilobase hot spots that show 10-100 fold greater recombination than the background rate [15]. Equally, large chromosome regions are recombination cold spots, notably including the centromeres [16*-19] (Fig. 1). For example, many important crop plant species show pronounced distal skews of crossover frequency towards sub-telomeric regions, away from the centromeres $\left[17^{*}, 18,20,21\right]$. One reason for recombination-suppression within centromeres is that proximal crossovers have been associated with higher rates of aneuploidy in fungi and animals, including in human trisomy [22]. In this review, we examine the genetic and epigenetic organization of plant centromeres and how this relates to patterns of meiotic recombination. We discuss the potential roles that recombination may play in driving centromere evolution. Finally, we consider how new sequencing technologies will advance the study of plant centromeres and some of the outstanding questions to be addressed.

\section{Genetic and epigenetic features of plant centromeres:}

The primary function of centromeres is to assemble the kinetochore, a multi-megadalton protein complex that connects chromosomes to spindle microtubules during mitotic and meiotic segregation (Fig. 1A) [23]. Kinetochore position is epigenetically determined by nucleosomes 
containing the histone 3 variant CENP-A/CENH3 [23-25]. Mammalian CENP-A nucleosomes directly bind the core kinetochore proteins CENP-N and CENP-C [23], and CENP-C plays a conserved role in maize [26]. CENP proteins form the constitutive centromere-associated network (CCAN), which further interacts with the KNL1-Mis12-Ndc80 (KMN) network to bind the spindle microtubules [23]. Homologs of the KMN network have been shown to play a conserved role in plant centromeres and kinetochore attachment to spindle microtubules [4,27-29].

CENH3 possesses a histone-fold domain that is similar to histone 3 , but its $\mathrm{N}$-terminal tail is highly divergent $[24,30]$. The histone fold domain is required to target CENH3/CENP-A to the centromere [23,31-33]. In Arabidopsis, transgenes expressing a GFP-tailswap CENH3 protein, with the N-terminus exchanged with histone 3.3 , are able to complement cenh3 lethality [28*]. However, GFP-tailswap CENH3 is not loaded during meiosis, causing sterility [28*]. This implies meiosis-specific CENH3 loading mechanisms in plants that require the $\mathrm{N}$-terminal tail. This is also consistent with observations of biphasic $\mathrm{CENH} 3$ loading during rye meiosis [34]. Despite the conserved function of CENH3/CENP-A remarkable levels of sequence divergence between species are observed, which may reflect meiotic drive caused by genetic conflicts [35].

In most plants, the DNA sequences underlying the centromeres consist of megabase arrays of tandemly repeated satellite sequences, interspersed with Gypsy LTR retrotransposons [36-39]. For example, Arabidopsis centromeres consist of 180 bp CEN180 satellite arrays interspersed with ATHILA retrotransposons (Fig. 1C and 2) $\left[19,37^{*}\right]$. Satellite monomers are frequently of similar length to that occupied by a nucleosome ( 147 bp) For example, Arabidopsis CEN180=180 nt, maize $C e n t C=156 \mathrm{nt}$ and rice $C e n t O=155 \mathrm{nt}$, although monomer sequences are poorly conserved beyond 50 million years of divergence $\left[37^{*}, 39-41\right]$. CENH3 occupancy mapped by ChIP-seq typically shows enrichment on a subset of the centromeric satellite arrays and retrotransposons [37*-39,42-44]. Many Gypsy LTR retrotransposons that predominate in plant centromeres belong to the Chromovirus family, which are typified by integrasechromodomain fusions [36]. Interestingly, such chromodomains are sufficient to target heterochromatin in plants and fungi $\left[45^{\star}\right]$. However, it is noteworthy that the Tal1 COPIA retrotransposon from Arabidopsis lyrata shows a strong preference for centromeric insertion when introduced into A.thaliana, despite lacking an integrase-chromodomain [46].

The high divergence of satellite and CENH3 sequences between species suggests meiotic drive and potentially co-evolution [35]. However, transformation of Arabidopsis cenh3 mutants with CENH3 from other species (A.arenosa, L.oleraceum, B.rapa, Z.mays and V.vinifera) results in complementation and normal centromere localization, measured via immunolocalization and ChIP $\left[37^{*}, 47,48\right]$. Cross species centromere loading of CENH3 has also been observed in oatmaize addition lines and in barley hybrids $[49,50]$. This shows that CENH3 loading can occur on divergent satellite sequences. However, following crossing of Arabidopsis cenh 3 complemented lines with wild type, the resulting progeny include haploids and anueploids, due to the chromosomes loaded with the variant CENH3 being lost early during embryogenesis $\left[47,51^{*}\right]$. CENH3-mediated genome elimination in Arabidopsis associates with formation of micronuclei in embryonic cells, chromosome shattering and repair via non-homologous end joining (NHEJ) [52*], which is likely related to the phenomenon of chromothripsis seen in cancer [53]. CENH3mediated genome elimination demonstrates the potent effect that centromere variation can exert on chromosome transmission and has powerful potential applications in plant breeding $\left[48,51^{*}\right]$.

A classical demonstration of the epigenetic flexibility of centromeres, is via formation of neocentromeres, for example following deletion of the endogenous centromere [54]. Neocentromeres have been found in diverse species and may form on unique or repeated 
sequences that lack centromeric satellites and retrotransposons $\left[55^{*}, 56\right]$. This implies that established centromeres normally suppress formation of incipient neocentromeres. Indeed, this was directly seen in maize dicentric chromosomes, where one of the former centromeres is suppressed [57]. Centromere location is typically stable in maize, although some drift of CENH3 domains mapped by ChIP-seq between maize siblings occurs, over a distance of $\sim 100 \mathrm{~kb}\left[55^{\star}\right]$. In oat-maize addition lines, that carry a single maize chromosome combined with the oat genome, the maize centromere expands to twice the size, and in some cases relocates [58*]. This indicates trans modification of maize centromere organization by the oat chromosomes. There are also notable departures from monocentric architecture in holocentric and polycentric plants, where $\mathrm{CENH} 3$ occupancy and kinetochores are distributed along the entire length of the chromosomes or at multiple locations, respectively $[59,60]$.

A further common feature of most plant centromeres is enrichment of transposable elements (TEs) and other repeats, flanking the centromeric satellite arrays, termed pericentromeric heterochromatin (Fig. 1B) [61]. Plant heterochromatin is epigenetically modified with an array of chromatin modifications including $\mathrm{CG}, \mathrm{CHG}$ and $\mathrm{CHH}$ DNA methylation, histone H3K9me2, H3K27me1 and histone variant H2A.W [62-65]. These marks contribute to increased nucleosome density, cytological condensation, A/B compartment structure, late-replication, suppressed meiotic recombination, suppressed RNA polymerase II transcription and elevated RNA polymerase IV and $V$ transcription, in these regions $\left[16^{*}, 62-67\right]$. Mutants that disrupt heterochromatin cause varying changes to transcription and recombination in the pericentromeres $\left[16^{*}, 62-66\right]$. However, to date plant heterochromatin mutants have not been observed to show defects in chromosome segregation [61]. In contrast, disruption of pericentromeric heterochromatin in fission yeast causes loss of centromeric cohesion and aneuploidy [68]. However, as redundant pathways maintain plant heterochromatin, removal of multiple epigenetic marks simultaneously may be necessary to influence centromere function and chromosome segregation.

\section{Suppression of meiotic recombination in plant centromeres:}

The totality of factors that limit crossover formation within and in proximity to centromeres remains unclear. One possibility could be restriction of the initial precursor DSBs. During catalysis SPO11-1 becomes covalently bound to target site oligonucleotides, which can be sequenced to generate maps of meiotic DSBs $\left[16^{*}, 69\right]$. For example, Arabidopsis SP011-1oligonucleotides show relative suppression within pericentromeric heterochromatin (Fig. 1B) [16*]. In contrast, SPO11-1 ChIP-seq shows enrichment in Arabidopsis pericentromeric heterochromatin [70]. This implies that DSB formation by SPO11-1 is not limited by its presence on the meiotic axis, and that other steps are required to activate recombination. This is in agreement with observations in budding yeast whose centromeres are DSB suppressed, even when Spo11 is artificially tethered there $\left[71^{*}, 72\right]$. A second broad possibility is that crossover repair in centromeres could be suppressed downstream of DSB formation. For example, meiotic DSB repair within the centromeres may favour inter-sister or non-crossover pathways, instead of crossover. Support for this model is provided in maize centromeres, where meiotic DSB activity, measured by RAD51 foci or ChIP-seq signal or gene conversion, has been detected, yet crossovers are absent $\left[73^{*}, 74^{*}\right]$. We consider three mechanisms with the potential to suppress meiotic DSBs, or downstream crossover repair, in the centromeres: (i) epigenetic factors, including histone modifications and DNA methylation, (ii) genetic variation, including inter-homolog structural polymorphism, and (iii) non-histone chromosomal proteins, including the kinetochore and cohesin. 
The role of heterochromatin in suppression of meiotic crossover has been studied in Arabidopsis. For example, RNA directed DNA methylation (RdDM) targeted to crossover hot spots located in euchromatin caused acquisition of dense CG, CHG and CHH DNA methylation, H3K9me2, higher nucleosome density and suppressed crossovers [75*]. However, at the chromosome-scale, loss of DNA methylation in CG (e.g. met1) versus non-CG (e.g. kryptonite/suvh4 suvh5 suvh6) contexts has different effects on centomere-proximal crossovers $\left[16^{*}, 64^{*}, 75^{*}\right]$. Despite both classes of mutant showing increased SPO11-1-oligos in the centromeric and pericentromeric regions, CG mutants show decreased crossovers and non-CG mutants show increased crossovers $\left[16^{*}, 64^{*}, 75^{\star}\right]$. Importantly, H3K9me2 remains in CG mutant centromeres [76], but is reduced or absent in non-CG mutants [63,64*]. Hence, H3K9me2 may suppress crossover maturation in met1 centromeres, despite increased DSBs. This leads to a model where DSBs may be widespread throughout heterochromatin, and perhaps centromeres, but are suppressed from crossover maturation by epigenetic marks, including H3K9me2. Suppression of centromeric crossovers in hybrid plants may also be attributed to structural variation in satellites arrays, including inversions $[77,78]$.

Evidence exists for non-histone chromosomal proteins regulating crossovers in centromeres. For example, the kinetochore CCAN/Ctf19 complex suppresses recombination in vicinity of the budding yeast centromeres, in addition to promoting cohesin loading $\left[71^{*}, 79\right]$. As cohesins favour DSB repair with sister chromatids rather than homologs $[80,81]$, pericentromeric cohesin enrichment could thereby limit interhomolog recombination. Indeed, ChIP-seq of REC8 (the meiosis-specific a-kleisin cohesin subunit) in Arabidopsis, has shown enrichment within pericentromeres, which negatively correlates with meiotic DSBs and crossovers [70]. In fission yeast, a specific cohesin complex, Rec8-Psc3, acts to repress meiotic recombination in the pericentromeres [82]. Pericentromeric enrichment of cohesin in fission yeast is also dependent upon H3K9 methylation and heterochromatin protein Swi6 [68,83,84]. In contrast, in mice centromeric cohesion is maintained in suv39h-1 suv39h-2 H3K9 methylation mutants during mitosis, although remodeling of cohesin occupancy occurs on specific repeats $[85,86]$. In Arabidopsis loss of $\mathrm{H} 3 \mathrm{~K} 9 \mathrm{me} 2$ and non-CG DNA methylation in kyp suvh5 suvh6 triple mutants causes remodeling of REC8, which is associated with gain of meiotic recombination in repeats, although as in mice, centromere cohesion is maintained $\left[64^{*}, 70\right]$.

\section{Evidence for recombination in plant centromeres:}

Suppression of meiotic recombination in centromeres is a conserved phenomenon [22]. However, the evolution of tandem arrays of satellite repeats, which often show higher order duplications (e.g. Fig. 2), implies that DNA repair and recombination has nevertheless occurred. Possible recombination-dependent mechanisms for satellite expansion or contraction include, (i) somatic homologous and non-homologous recombination, (ii) unequal meiotic crossover and (iii) meiotic gene conversion. Interspersed centromeric retroelements may also play a role in generating sequence change, acting either as recombination substrates, or via transpositional effects [87]. Recombination-independent mechanisms, such as replication slippage, could also play a role [88]. We will consider the evidence for these different modes of recombination and their potential to drive satellite duplication in plant centromeres.

Somatic homologous recombination (HR) in plants has been studied using transgenes, where homologous recombination between GUS sequences on the same or different T-DNAs restores $\beta$-glucuronidase activity $[89,90]$. Recombination measured using these assays shows the classic features of HR, including a suppressive effect caused by substrate divergence and RAD51-dependence $[89,90]$. Hence, it is possible that somatic DSBs occurring in the satellite arrays could be repaired non-allelically via HR pathways, which could cause monomer 
duplications and deletions, or higher order changes. Evidence for the action of non-homologous pathways, including microhomology mediated DSB repair, also exists in maize centromeres [78]. For such somatic changes to have transgenerational significance, the mutations must occur in a clone of cells that leads to germ line differentiation. For example, tomato site-specific induced DSBs have been shown to cause somatic HR mediated repair, which led to genetic changes transmitted to progeny [91].

A second broad possibility is that meiotic recombination causes changes to the satellite arrays, which would transmit between generations via the gametes. For example, following SPO11-1 dependent DSB formation, resection and strand invasion, repeat sequences may misalign with non-allelic repeats. If crossover proceeds in this situation then unequal exchange may occur, creating duplications or deletions of the associated repeats. For example, unequal crossover has also been proposed to generate structural diversity in plant disease resistance gene clusters [92,93]. Analysis of rice and maize centromere sequences has revealed segmental duplications of CentO/CentC satellite repeats consistent with unequal recombination [78,94]. However, direct observation of unequal crossover in plant satellite repeats is so far lacking, and crossovers are typically suppressed in the centromeres (Fig. 1C) [16*-18,20,74*]. A further possibility is meiotic gene conversion. As discussed earlier, the majority of meiotic interhomolog strand invasion events are dissolved via anti-crossover activities, in which case the ssDNA returns to the parent homolog and is repaired as a non-crossover [1]. Supporting a role of meiotic gene conversion, genetic mapping within maize centromeres has revealed conversion of CRM retrotransposons, but an absence of meiotic crossovers [74*]. Further study of plant centromere sequence stability in wild type and mutant backgrounds will be required to investigate the contributions of these varying recombination pathways.

\section{New technologies and open questions}

A major challenge to studying centromeres is that the megabase arrays of satellites remain difficult to sequence and assemble. However, new DNA sequencing and analysis technologies promise to make this more widely achievable. First, optical mapping techniques allow genomewide physical assemblies to be obtained [95]. For example, Bionano technology allows megabase length DNA molecules to be fluorescently labeled at restriction sites, linearized and directly visualized during microfluidic separation. This generates a genome-wide restriction map, that can be used to anchor and orientate sequence contigs [95]. Second, high throughput sequencing technologies that provide longer read lengths (kilobase to megabase), including Pacific Biosystems, Oxford Nanopore and 10x Genomics, promise to dramatically improve centromere assemblies. These technologies will allow satellite array dynamics to be investigated within and between generations, in order to address the role of somatic versus germline homologous recombination. A range of mutations are available in model plant species that disrupt recombination, cohesin, chromatin and the kinetochore. Assembly of centromere sequences in these mutants, using new technologies may allow effects on satellite sequence stability to be tested.

Recombination suppression in the centromeres is observed in the majority of eukaryotes [16*$19,22]$. Candidate factors that may repress meiotic DSBs, or promote inter-sister and noncrossover repair, in the centromeres, include chromatin, cohesin, kinetochore occupancy or structural heterozygosity. Interestingly, the SMC4 condensin gene was genetically identified as playing a role in heterochromatic silencing via DNA methylation in Arabidopsis [96*]. Hence, interactions between cohesin, condensin and chromatin, and their roles in shaping meiotic DSB and crossover frequency within plant centromeres will be interesting to further explore. It is also possible that CENH3 may contribute to suppression of meiotic recombination in plant genomes, 
although this remains untested. The environment may influence levels of recombination close to the centromeres. For example, elevated temperature $\left(25^{\circ} \mathrm{C}\right.$ or $\left.30^{\circ} \mathrm{C}\right)$ increased crossovers genome-wide in barley and caused a shift towards interstitial and centromere-proximal regions [97]. Interestingly, in Brassica allotriploid AAC hybrids, a global recombination increase occurs in the A genome, including in centromere-proximal regions, compared to AA diploids, which may imply trans modification by the $\mathrm{C}$ genome [98].

Ultimately, a detailed understanding of plant centromere DNA sequence composition and chromatin promises to provide insight into their evolutionary dynamics. Satellite sequences show rapid divergence between species and evidence of concerted change across chromosomes. In some cases the youngest satellites correspond to CENH3/CENP-A occupied sequences, with older satellites and transposon sequences located distally to the kinetochore $\left[37^{*}, 38,99,100\right]$. Gene conversion is one mechanism whereby concerted evolution and homogenization of sequences may occur $\left[74^{*}, 101\right]$. Targeted transposition may further allow centromeres on different chromosomes to acquire the same repeats [87]. Trans modifier loci can also influence centromere behavior. For example, the maize Abnormal chromosome 10 (Ab10) locus causes heterochromatic knobs to acquire 'neocentromere' identity and migrate to the cell poles faster than the established centromeres [102], although interestingly the neocentromere-knobs do not stain for CENP-C [26]. Ab10 can thus cause meiotic drive in knoblinked regions and was recently identified as a cluster of kinesin genes [103*]. It will be interesting to further define the role that recombination plays in driving evolution of satellite arrays and similar centromere-modifier loci, and thereby influencing the potential for genetic conflicts during meiosis.

\section{Figure Legends}

Figure 1. Meiotic recombination is suppressed in Arabidopsis centromeres. A. A schematic diagram of Arabidopsis thaliana chromosome 1 at pachytene is shown. Replicated sister chromatids are tethered by cohesin rings (red). Homologous chromosomes are labeled $\mathrm{m}$ and $p$, and joined via the synaptonemal complex (SC, green). MLH1 and HEI10 (blue) label large foci/nodules that correspond to Class I crossover sites. In the centromeres, H3 (blue) is replaced with CENH3-containing nucleosomes. Spindle microtubules (pink) attach to CENH3 chromatin, with sister chromatid kinetochores mono-orientated towards the same cell pole. Diagram is not to scale. B. Meiotic DSB frequency, measured by SPO11-1-oligonucleotides, plotted along chromosome 1 (red) $\left[16^{*}\right]$, plotted alongside DNA methylation (blue) $\left[75^{\star}\right]$. The position of the centromeric assembly gap is indicated by the vertical dotted line. C. As for $B$, but showing meiotic crossover frequency (red), measured by sequencing Col×Ler $F_{2}$ plants [16*], compared to Gypsy LTR (blue) and CACTA/EnSpm (pink) transposon density. Matches to the CEN180 consensus sequence are shown along the $\mathrm{x}$-axis, colored according to forward (red) or reverse (blue) strand mapping. Beneath is a representation of the estimated $9 \mathrm{Mb}$ of unassembled centromere sequence, which is thought to consist predominantly of CEN180 satellites [104].

Figure 2. Sequence composition of the Arabidopsis thaliana centromeric regions. A. Annotation of a 234 kilobase region of chromosome 1 from the TAIR10 assembly that is located in proximity to the centromere. Sequences are colored according to homology with CEN180 satellites (yellow), Gypsy LTR retrotransposons (red) and CACTA/EnSpm DNA transposons (pink). B. Dot plot analysis of the region shown in A, where shading indicates pairwise sequence identity, using word sizes of 15 and 130 nucleotides. The colored shading on the axes matches the sequence annotation shown in $\mathrm{A}$. 
Acknowledgements:

We thank Andrew Tock for input on Figure 1 and the reviewers for useful feedback. We acknowledge grant support from the ERC (PoC HEIREC), EMBO (Long Term Fellowship to JBF), Marie-Curie MEICOM ITN (PW) and ERC CoG SynthHotSpot (IRH) for support.

\section{REFERENCES:}

1. Mercier R, Mézard C, Jenczewski E, Macaisne N, Grelon M: The molecular biology of meiosis in plants. Annu Rev Plant Biol 2015, 66:297-327.

2. Uhlmann F, Nasmyth K: Cohesion between sister chromatids must be established during DNA replication. Curr Biol 1998, 8:1095-101.

3. Hunter N: Meiotic Recombination: The Essence of Heredity. Cold Spring Harb Perspect Biol 2015, 7:a016618.

4. Li X, Dawe RK: Fused sister kinetochores initiate the reductional division in meiosis I. Nat Cell Biol 2009, 11:1103-1108.

5. Chelysheva L, Diallo S, Vezon D, Gendrot G, Vrielynck N, Belcram K, Rocques N, Márquez-Lema A, Bhatt AM, Horlow C, et al.: AtREC8 and AtSCC3 are essential to the monopolar orientation of the kinetochores during meiosis. J Cell Sci 2005, 118:4621-32.

6. * Vrielynck N, Chambon A, Vezon D, Pereira L, Chelysheva L, De Muyt A, Mézard C, Mayer C, Grelon M: A DNA topoisomerase VI-like complex initiates meiotic recombination. Science 2016, 351:939-43.

7. * Robert T, Nore A, Brun C, Maffre C, Crimi B, Bourbon H-M, de Massy B: The TopoVIBLike protein family is required for meiotic DNA double-strand break formation. Science (80- ) 2016, 351:943-949.

* References 6 and 7 reveal that meiotic DSBs are generated by a topoisomerase-like complex conserved betweem plants and animals.

8. Neale MJ, Pan J, Keeney S: Endonucleolytic processing of covalent protein-linked DNA double-strand breaks. Nature 2005, 436:1053-7.

9. Gray S, Cohen PE: Control of Meiotic Crossovers: From Double-Strand Break Formation to Designation. Annu Rev Genet 2016, 50:175-210.

10. Sun Y, Ambrose JH, Haughey BS, Webster TD, Pierrie SN, Muñoz DF, Wellman EC, Cherian S, Lewis SM, Berchowitz LE, et al.: Deep genome-wide measurement of meiotic gene conversion using tetrad analysis in Arabidopsis thaliana. PLoS Genet 2012, 8:e1002968.

11. Lu P, Han X, Qi J, Yang J, Wijeratne AJ, Li T, Ma H: Analysis of Arabidopsis genomewide variations before and after meiosis and meiotic recombination by resequencing Landsberg erecta and all four products of a single meiosis. Genome Res 2012, 22:508-18.

12. Wijnker E, Velikkakam James G, Ding J, Becker F, Klasen JR, Rawat V, Rowan BA, de Jong DF, de Snoo CB, Zapata $L$, et al.: The genomic landscape of meiotic crossovers and gene conversions in Arabidopsis thaliana. Elife 2013, 2:e01426.

13. Cifuentes M, Rivard M, Pereira L, Chelysheva L, Mercier R: Haploid Meiosis in Arabidopsis: Double-Strand Breaks Are Formed and Repaired but Without Synapsis and Crossovers. PLoS One 2013, 8:e72431.

14. Fernandes JB, Duhamel M, Seguéla-Arnaud M, Froger N, Girard C, Choinard S, Solier V, De Winne N, De Jaeger G, Gevaert K, et al.: FIGL1 and its novel partner FLIP form a conserved complex that regulates homologous recombination. PLOS Genet 2018, 14:e1007317.

15. Choi K, Henderson IR: Meiotic recombination hotspots - a comparative view. Plant $J$ 2015, 83:52-61. 
16. * Choi K, Zhao X, Tock AJ, Lambing C, Underwood CJ, Hardcastle TJ, Serra H, Kim J, Cho HS, Kim J, et al.: Nucleosomes and DNA methylation shape meiotic DSB frequency in Arabidopsis thaliana transposons and gene regulatory regions. Genome Res 2018, doi:10.1101/gr.225599.117.

* Sequencing of SP011-1-oligonucleotides provides a genome-wide map of meiotic DSBs in Arabidopsis and relates this to chromatin, including nucleosome structure.

17. * Mascher M, Gundlach H, Himmelbach A, Beier S, Twardziok SO, Wicker T, Radchuk V, Dockter C, Hedley PE, Russell J, et al.: A chromosome conformation capture ordered sequence of the barley genome. Nature 2017, 544:427-433.

* Hi-C analysis of the complex barley genome reveals the Rabl configuration and provides insight into the higher order structure of a large crop genome.

18. Choulet F, Alberti A, Theil S, Glover N, Barbe V, Daron J, Pingault L, Sourdille P, Couloux $A$, Paux $E$, et al.: Structural and functional partitioning of bread wheat chromosome 3B. Science 2014, 345:1249721.

19. Copenhaver GP, Nickel K, Kuromori T, Benito MI, Kaul S, Lin X, Bevan M, Murphy G, Harris B, Parnell LD, et al.: Genetic definition and sequence analysis of Arabidopsis centromeres. Science 1999, 286:2468-74.

20. Higgins JD, Perry RM, Barakate A, Ramsay L, Waugh R, Halpin C, Armstrong SJ, Franklin FCH: Spatiotemporal asymmetry of the meiotic program underlies the predominantly distal distribution of meiotic crossovers in barley. Plant Cell 2012, 24:4096-109.

21. Darrier B, Rimbert H, Balfourier F, Pingault L, Josselin A-A, Servin B, Navarro J, Choulet F, Paux E, Sourdille P: High-Resolution Mapping of Crossover Events in the Hexaploid Wheat Genome Suggests a Universal Recombination Mechanism. Genetics 2017, 206:1373-1388.

22. Nambiar M, Smith GR: Repression of harmful meiotic recombination in centromeric regions. Semin Cell Dev Biol 2016, 54:188-197.

23. McKinley KL, Cheeseman IM: The molecular basis for centromere identity and function. Nat Rev Mol Cell Biol 2016, 17:16-29.

24. Talbert, Masuelli, Tyagi, Comai, Henikoff: Centromeric localization and adaptive evolution of an Arabidopsis histone H3 variant. Plant Cell 2002, doi:10.1105/tpc.010425.

25. Earnshaw WC, Rothfield N: Identification of a family of human centromere proteins using autoimmune sera from patients with scleroderma. Chromosoma 1985, doi:10.1007/BF00328227.

26. Dawe RK, Reed LM, Yu HG, Muszynski MG, Hiatt EN: A maize homolog of mammalian CENPC is a constitutive component of the inner kinetochore. Plant Cell 1999, 11:1227-38.

27. Sato H, Shibata F, Murata M: Characterization of a Mis12 homologue in Arabidopsis thaliana. Chromosom Res 2005, doi:10.1007/s10577-005-1016-3.

28. * Ravi M, Shibata F, Ramahi JS, Nagaki K, Chen C, Murata M, Chan SWL: Meiosisspecific loading of the centromere-specific histone CENH3 in Arabidopsis thaliana. PLoS Genet 2011, 7:e1002121.

* Analysis of CENH3 fusion proteins, where the N-terminal tail is replaced with the tail of histone 3.3, reveal that meiosis-specific loading mechanisms exist in this species.

29. Du Y, Dawe RK: Maize NDC80 is a constitutive feature of the central kinetochore. Chromosom Res 2007, doi:10.1007/s10577-007-1160-z.

30. Henikoff S, Ahmad K, Malik HS: The centromere paradox: Stable inheritance with rapidly evolving DNA. Science (80- ) 2001, doi:10.1126/science.1062939.

31. Lermontova I, Schubert V, Fuchs J, Klatte S, Macas J, Schubert I: Loading of Arabidopsis Centromeric Histone CENH3 Occurs Mainly during G2 and Requires 
the Presence of the Histone Fold Domain. PLANT CELL ONLINE 2006, doi:10.1105/tpc.106.043174.

32. Kuppu S, Tan EH, Nguyen H, Rodgers A, Comai L, Chan SWL, Britt AB: Point Mutations in Centromeric Histone Induce Post-zygotic Incompatibility and Uniparental Inheritance. PLOS Genet 2015, 11:e1005494.

33. Karimi-Ashtiyani R, Ishii T, Niessen M, Stein N, Heckmann S, Gurushidze M, BanaeiMoghaddam AM, Fuchs J, Schubert V, Koch K, et al.: Point mutation impairs centromeric CENH3 loading and induces haploid plants. Proc Natl Acad Sci 2015, doi:10.1073/pnas.1504333112.

34. Schubert V, Lermontova I, Schubert I: Loading of the centromeric histone H3 variant during meiosis-how does it differ from mitosis? Chromosoma 2014, 123:491-497.

35. Kursel LE, Malik HS: The cellular mechanisms and consequences of centromere drive. Curr Opin Cell Biol 2018, doi:10.1016/j.ceb.2018.01.011.

36. Sharma A, Presting GG: Evolution of centromeric retrotransposons in grasses. Genome Biol Evol 2014, doi:10.1093/gbe/evu096.

37. * Maheshwari S, Ishii T, Brown CT, Houben A, Comai L: Centromere location in Arabidopsis is unaltered by extreme divergence in CENH3 protein sequence. Genome Res 2017, 27:471-478.

* Detailed analysis of Arabidopsis satellite sequences is presented, together with CENH3 ChIPseq data identifying the functional centromere.

38. Wolfgruber TK, Sharma A, Schneider KL, Albert PS, Koo D-H, Shi J, Gao Z, Han F, Lee $\mathrm{H}$, Xu R, et al:: Maize Centromere Structure and Evolution: Sequence Analysis of Centromeres 2 and 5 Reveals Dynamic Loci Shaped Primarily by Retrotransposons. PLoS Genet 2009, 5:e1000743.

39. Zhang T, Talbert PB, Zhang W, Wu Y, Yang Z, Henikoff JG, Henikoff S, Jiang J: The CentO satellite confers translational and rotational phasing on cenH3 nucleosomes in rice centromeres. Proc Natl Acad Sci 2013, doi:10.1073/pnas.1319548110.

40. Melters DP, Bradnam KR, Young HA, Telis N, May MR, Ruby JG, Sebra R, Peluso P, Eid $J$, Rank $D$, et al.: Comparative analysis of tandem repeats from hundreds of species reveals unique insights into centromere evolution. Genome Biol 2013, 14:R10.

41. Bilinski P, Distor K, Gutierrez-Lopez J, Mendoza GM, Shi J, Dawe RK, Ross-Ibarra J: Diversity and evolution of centromere repeats in the maize genome. Chromosoma 2015, 124:57-65.

42. Nagaki K, Talbert PB, Zhong CX, Dawe RK, Henikoff S, Jiang J: Chromatin Immunoprecipitation Reveals That the 180-bp Satellite Repeat Is the Key Functional DNA Element of Arabidopsis thaliana Centromeres. Genetics 2003, 163.

43. Zhong CX, Marshall JB, Topp C, Mroczek R, Kato A, Nagaki K, Birchler JA, Jiang J, Dawe RK: Centromeric retroelements and satellites interact with maize kinetochore protein CENH3. Plant Cell 2002, 14:2825-36.

44. Houben A, Schroeder-Reiter E, Nagaki K, Nasuda S, Wanner G, Murata M, Endo TR: CENH3 interacts with the centromeric retrotransposon cereba and GC-rich satellites and locates to centromeric substructures in barley. Chromosoma 2007, 116:275-283.

45. * Gao X, Hou Y, Ebina H, Levin HL, Voytas DF: Chromodomains direct integration of retrotransposons to heterochromatin. Genome Res 2008, 18:359-69.

* Analysis of Gypsy LTR transposon chromodomains indicate a function in targeting heterochromatin, providing a means for transposons to target centromeres.

46. Tsukahara S, Kawabe A, Kobayashi A, Ito T, Aizu T, Shin-i T, Toyoda A, Fujiyama A, Tarutani $\mathrm{Y}$, Kakutani T: Centromere-targeted de novo integrations of an LTR retrotransposon of Arabidopsis lyrata. Genes Dev 2012, 26:705-713.

47. Maheshwari S, Tan EH, West A, Franklin FCH, Comai L, Chan SWL: Naturally 
occurring differences in CENH3 affect chromosome segregation in zygotic mitosis of hybrids. PLoS Genet 2015, 11:e1004970.

48. Ravi M, Kwong PN, Menorca RMG, Valencia JT, Ramahi JS, Stewart JL, Tran RK, Sundaresan V, Comai L, Chan SW-L: The rapidly evolving centromere-specific histone has stringent functional requirements in Arabidopsis thaliana. Genetics 2010, 186:461-71.

49. Jin W, Melo JR, Nagaki K, Talbert PB, Henikoff S, Dawe RK, Jiang J: Maize Centromeres: Organization and Functional Adaptation in the Genetic Background of Oat. PLANT CELL ONLINE 2004, 16:571-581.

50. Sanei M, Pickering R, Kumke K, Nasuda S, Houben A: Loss of centromeric histone H3 (CENH3) from centromeres precedes uniparental chromosome elimination in interspecific barley hybrids. Proc Natl Acad Sci 2011, doi:10.1073/pnas.1103190108.

51. * Ravi M, Chan SWL: Haploid plants produced by centromere-mediated genome elimination. Nature 2010, 464:615-8.

* Ground-breaking study showing that modifications to CENH3 could cause genome elimination when fusion proteins are competed against wild type variants.

52. * Tan EH, Henry IM, Ravi M, Bradnam KR, Mandakova T, Marimuthu MP, Korf I, Lysak MA, Comai L, Chan SW: Catastrophic chromosomal restructuring during genome elimination in plants. Elife 2015, 4.

* CENH3-mediated genome-elimination was found to associate with micronuclei and chromosome shattering in the early embryonic divisions.

53. Zhang CZ, Spektor A, Cornils H, Francis JM, Jackson EK, Liu S, Meyerson M, Pellman D: Chromothripsis from DNA damage in micronuclei. Nature 2015, doi:10.1038/nature14493.

54. Scott KC, Sullivan BA: Neocentromeres: A place for everything and everything in its place. Trends Genet 2014, doi:10.1016/j.tig.2013.11.003.

55. * Gent JI, Wang N, Dawe RK: Stable centromere positioning in diverse sequence contexts of complex and satellite centromeres of maize and wild relatives. Genome Biol 2017, 18:121.

* Interesting study profiling the stability of centromere locations in maize populations using CENH3 ChIP-seq.

56. Su H, Liu Y, Liu Y-X, Lv Z, Li H, Xie S, Gao Z, Pang J, Wang X-J, Lai J, et al.: Dynamic chromatin changes associated with de novo centromere formation in maize euchromatin. Plant $J$ 2016, 88:854-866.

57. Han F, Lamb JC, Birchler JA: High frequency of centromere inactivation resulting in stable dicentric chromosomes of maize. Proc Natl Acad Sci 2006, doi:10.1073/pnas.0509650103.

58. * Wang K, Wu Y, Zhang W, Dawe RK, Jiang J: Maize centromeres expand and adopt a uniform size in the genetic background of oat. Genome Res 2014, 24:107-16.

* Oat-maize addition lines show that maize centromeres increase in size when exposed to the larger oat chromosomes.

59. Heckmann S, Jankowska M, Schubert V, Kumke K, Ma W, Houben A: Alternative meiotic chromatid segregation in the holocentric plant Luzula elegans. Nat Commun 2014, doi:10.1038/ncomms5979.

60. Cuacos M, H. Franklin FC, Heckmann S: Atypical centromeres in plants-what they can tell us. Front Plant Sci 2015, 6:913.

61. Topp CN, Dawe RK: Reinterpreting pericentromeric heterochromatin. Curr Opin Plant Biol 2006, 9:647-653.

62. Jacob Y, Stroud H, Leblanc C, Feng S, Zhuo L, Caro E, Hassel C, Gutierrez C, Michaels SD, Jacobsen SE: Regulation of heterochromatic DNA replication by histone H3 lysine 27 methyltransferases. Nature 2010, 466:987-91. 
63. Stroud H, Do T, Du J, Zhong X, Feng S, Johnson L, Patel DJ, Jacobsen SE: Non-CG methylation patterns shape the epigenetic landscape in Arabidopsis. Nat Struct Mol Biol 2014, 21:64-72.

64. * Underwood CJ, Choi K, Lambing C, Zhao X, Serra H, Borges F, Simorowski J, Ernst E, Jacob Y, Henderson IR, et al.: Epigenetic activation of meiotic recombination near Arabidopsis thaliana centromeres via loss of H3K9me2 and non-CG DNA methylation. Genome Res 2018, doi:10.1101/gr.227116.117.

* Loss of non-CG DNA methylation and H3K9me2 is shown to increase centromeric DSBs and crossovers in Arabidopsis.

65. Yelagandula R, Stroud H, Holec S, Zhou K, Feng S, Zhong X, Muthurajan UM, Nie X, Kawashima T, Groth $M$, et al.: The histone variant H2A.W defines heterochromatin and promotes chromatin condensation in Arabidopsis. Cell 2014, 158:98-109.

66. Feng S, Cokus SJ, Schubert V, Zhai J, Pellegrini M, Jacobsen SE: Genome-wide Hi-C analyses in wild-type and mutants reveal high-resolution chromatin interactions in Arabidopsis. Mol Cell 2014, 55:694-707.

67. Costas C, de la Paz Sanchez M, Stroud H, Yu Y, Oliveros JC, Feng S, Benguria A, López-Vidriero I, Zhang X, Solano R, et al.: Genome-wide mapping of Arabidopsis thaliana origins of DNA replication and their associated epigenetic marks. Nat Struct Mol Biol 2011, 18:395-400.

68. Bernard P, Maure JF, Partridge JF, Genier S, Javerzat JP, Allshire RC: Requirement of Heterochromatin for Cohesion at Centromeres. Science (80- ) 2001, 294:2539-2542.

69. Keeney S, Neale MJ: Initiation of meiotic recombination by formation of DNA double-strand breaks: mechanism and regulation. Biochem Soc Trans 2006, 34:5235 .

70. Lambing C, Tock AJ, Choi K, Topp SD, Kuo PC, Blackwell AR, Zhao X, Osman K, Higgins JD, Franklin FCH, et al.: REC8-cohesin, chromatin and transcription orchestrate meiotic recombination in the Arabidopsis genome. bioRxiv 2019, doi:10.1101/512400.

71. * Vincenten N, Kuhl L-M, Lam I, Oke A, Kerr AR, Hochwagen A, Fung J, Keeney S, Vader $G$, Marston AL: The kinetochore prevents centromere-proximal crossover recombination during meiosis. Elife 2015, 4.

* Demonstration that the CCAN kinetochore complex directly suppresses meiotic DSBs and crossovers in budding yeast.

72. Robine N, Uematsu N, Amiot F, Gidrol X, Barillot E, Nicolas A, Borde V: Genome-wide redistribution of meiotic double-strand breaks in Saccharomyces cerevisiae. Mol Cell Biol 2007, 27:1868-80.

73. * He Y, Wang M, Dukowic-Schulze S, Zhou A, Tiang C-L, Shilo S, Sidhu GK, Eichten S, Bradbury P, Springer NM, et al.: Genomic features shaping the landscape of meiotic double-strand-break hotspots in maize. Proc Natl Acad Sci U S A 2017, 114:1223112236.

* Genomic and cytological mapping of RAD51 indicates widespread DSB activity along maize chromosomes, including in proximity to the centromeres.

74. * Shi J, Wolf SE, Burke JM, Presting GG, Ross-lbarra J, Dawe RK: Widespread gene conversion in centromere cores. PLoS Biol 2010, 8:e1000327.

* Genetic analysis reveals CRM transposon gene conversion in maize centromeres, although crossover recombination was suppressed.

75. * Yelina NE, Lambing C, Hardcastle TJ, Zhao X, Santos B, Henderson IR: DNA methylation epigenetically silences crossover hot spots and controls chromosomal domains of meiotic recombination in Arabidopsis. Genes Dev 2015, 29:2183-202.

${ }^{*}$ RNA directed DNA methylation was used to epigenetically silence a crossover hotspot in 
Arabidopsis.

76. Deleris A, Stroud H, Bernatavichute $Y$, Johnson E, Klein G, Schubert D, Jacobsen SE: Loss of the DNA methyltransferase MET1 Induces H3K9 hypermethylation at PcG target genes and redistribution of H3K27 trimethylation to transposons in Arabidopsis thaliana. PLoS Genet 2012, 8:e1003062.

77. Ito H, Miura A, Takashima K, Kakutani T: Ecotype-specific and chromosome-specific expansion of variant centromeric satellites in Arabidopsis thaliana. Mol Genet Genomics 2007, 277:23-30.

78. Wolfgruber TK, Nakashima MM, Schneider KL, Sharma A, Xie Z, Albert PS, Xu R, Bilinski $P$, Dawe RK, Ross-lbarra J, et al.: High Quality Maize Centromere 10 Sequence Reveals Evidence of Frequent Recombination Events. Front Plant Sci 2016, 7:308.

79. Hinshaw SM, Makrantoni V, Harrison SC, Marston AL: The Kinetochore Receptor for the Cohesin Loading Complex. Cell 2017, doi:10.1016/j.cell.2017.08.017.

80. Kim KP, Weiner BM, Zhang L, Jordan A, Dekker J, Kleckner N: Sister cohesion and structural axis components mediate homolog bias of meiotic recombination. Cell 2010, 143:924-37.

81. Covo S, Westmoreland JW, Gordenin DA, Resnick MA: Cohesin Is Limiting for the Suppression of DNA Damage-Induced Recombination between Homologous Chromosomes. PLoS Genet 2010, 6:e1001006.

82. Nambiar M, Smith GR: Pericentromere-Specific Cohesin Complex Prevents Meiotic Pericentric DNA Double-Strand Breaks and Lethal Crossovers. Mol Cell 2018, doi:10.1016/j.molcel.2018.06.035.

83. Nonaka N, Kitajima T, Yokobayashi S, Xiao G, Yamamoto M, Grewal SIS, Watanabe Y: Recruitment of cohesin to heterochromatic regions by Swi6/HP1 in fission yeast. Nat Cell Biol 2002, 4:89-93.

84. Mizuguchi T, Fudenberg G, Mehta S, Belton J-M, Taneja N, Folco HD, FitzGerald P, Dekker J, Mirny L, Barrowman J, et al.: Cohesin-dependent globules and heterochromatin shape 3D genome architecture in S. pombe. Nature 2014, 516:432435.

85. Koch B, Kueng S, Ruckenbauer C, Wendt KS, Peters J-M: The Suv39h-HP1 histone methylation pathway is dispensable for enrichment and protection of cohesin at centromeres in mammalian cells. Chromosoma 2008, 117:199-210.

86. Guenatri M, Bailly D, Maison C, Almouzni G: Mouse centric and pericentric satellite repeats form distinct functional heterochromatin. J Cell Biol 2004, 166:493-505.

87. Birchler JA, Presting GG: Retrotransposon insertion targeting: a mechanism for homogenization of centromere sequences on nonhomologous chromosomes. Genes Dev 2012, 26:638-40.

88. Kim JC, Mirkin SM: The balancing act of DNA repeat expansions. Curr Opin Genet Dev 2013, 23:280-288.

89. Puchta $\mathrm{H}$, Hohn B: In planta somatic homologous recombination assay revisited: a successful and versatile, but delicate tool. Plant Cell 2012, 24:4324-31.

90. Vu GTH, Cao HX, Watanabe K, Hensel G, Blattner FR, Kumlehn J, Schubert I: Repair of Site-Specific DNA Double-Strand Breaks in Barley Occurs via Diverse Pathways Primarily Involving the Sister Chromatid. Plant Cell 2014, 26:2156-2167.

91. Filler Hayut S, Melamed Bessudo C, Levy AA: Targeted recombination between homologous chromosomes for precise breeding in tomato. Nat Commun 2017, 8:15605.

92. Parniske M, Hammond-Kosack KE, Golstein C, Thomas CM, Jones DA, Harrison K, Wulff BB, Jones JD: Novel disease resistance specificities result from sequence exchange between tandemly repeated genes at the $\mathrm{Cf}-4 / 9$ locus of tomato. Cell 1997, 91:821-832. 
93. Chin DB, Arroyo-Garcia R, Ochoa OE, Kesseli R V, Lavelle DO, Michelmore RW: Recombination and spontaneous mutation at the major cluster of resistance genes in lettuce (Lactuca sativa). Genetics 2001, 157:831-49.

94. Ma J, Wing RA, Bennetzen JL, Jackson SA: Plant centromere organization: a dynamic structure with conserved functions. Trends Genet 2007, 23:134-139.

95. Udall J, Dawe RK: Is it ordered correctly? Validating genome assemblies by optical mapping. Plant Cell 2017, doi:10.1105/tpc.17.00514.

96. * Wang J, Blevins T, Podicheti R, Haag JR, Tan EH, Wang F, Pikaard CS: Mutation of Arabidopsis SMC4 identifies condensin as a corepressor of pericentromeric transposons and conditionally expressed genes. Genes Dev 2017, 31:1601-1614.

* Genetic identification of the condensin protein SMC4 as playing a role in DNA methylation mediated gene silencing in plants.

97. Phillips D, Jenkins G, Macaulay M, Nibau C, Wnetrzak J, Fallding D, Colas I, Oakey H, Waugh R, Ramsay L: The effect of temperature on the male and female recombination landscape of barley. New Phytol 2015, 208:421-429.

98. Pele A, Falque M, Trotoux G, Eber F, Negre S, Gilet M, Huteau V, Lode M, Jousseaume $T$, Dechaumet $S$, et al.: Amplifying recombination genome-wide and reshaping crossover landscapes in Brassicas. PLOS Genet 2017, 13:e1006794.

99. Rudd MK, Wray GA, Willard HF: The evolutionary dynamics of alpha-satellite. Genome Res 2006, 16:88-96.

100. Jain M, Olsen HE, Turner DJ, Stoddart D, Bulazel K V., Paten B, Haussler D, Willard HF, Akeson M, Miga KH: Linear assembly of a human centromere on the $y$ chromosome. Nat Biotechnol 2018, doi:10.1038/nbt.4109.

101. Chalhoub B, Denoeud F, Liu S, Parkin IAP, Tang H, Wang X, Chiquet J, Belcram H, Tong $\mathrm{C}$, Samans B, et al.: Plant genetics. Early allopolyploid evolution in the postNeolithic Brassica napus oilseed genome. Science 2014, 345:950-3.

102. Yu HG, Hiatt EN, Chan A, Sweeney M, Dawe RK: Neocentromere-mediated chromosome movement in maize. $J$ Cell Biol 1997, 139:831-40.

103. * Dawe RK, Lowry EG, Gent JI, Stitzer MC, Swentowsky KW, Higgins DM, Ross-Ibarra J, Wallace JG, Kanizay LB, Alabady M, et al.: A Kinesin-14 Motor Activates

Neocentromeres to Promote Meiotic Drive in Maize. Cell 2018, 173:839-850.e18. * Identification of the Ab10 meiotic drive locus as encoding a cluster of kinesin genes that modify heterochromatic knob segregation.

104. Hosouchi T, Kumekawa N, Tsuruoka H, Kotani H: Physical map-based sizes of the centromeric regions of Arabidopsis thaliana chromosomes 1, 2, and 3. DNA Res 2002, 9:117-21. 
A

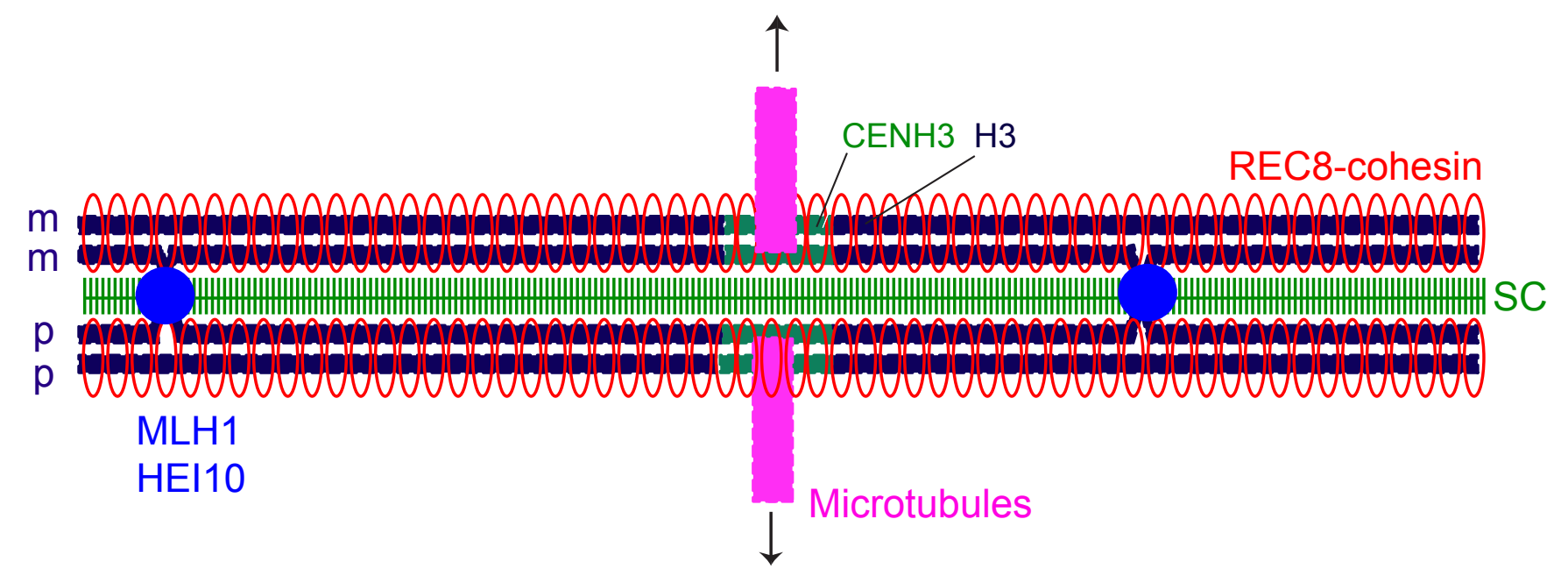

B

Chromosome 1

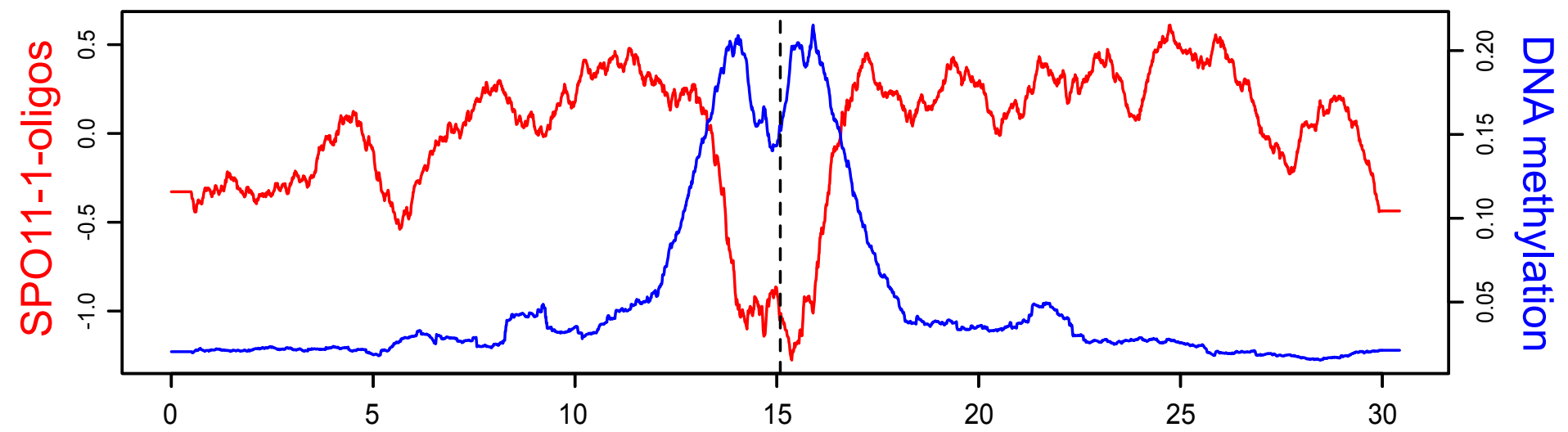

C

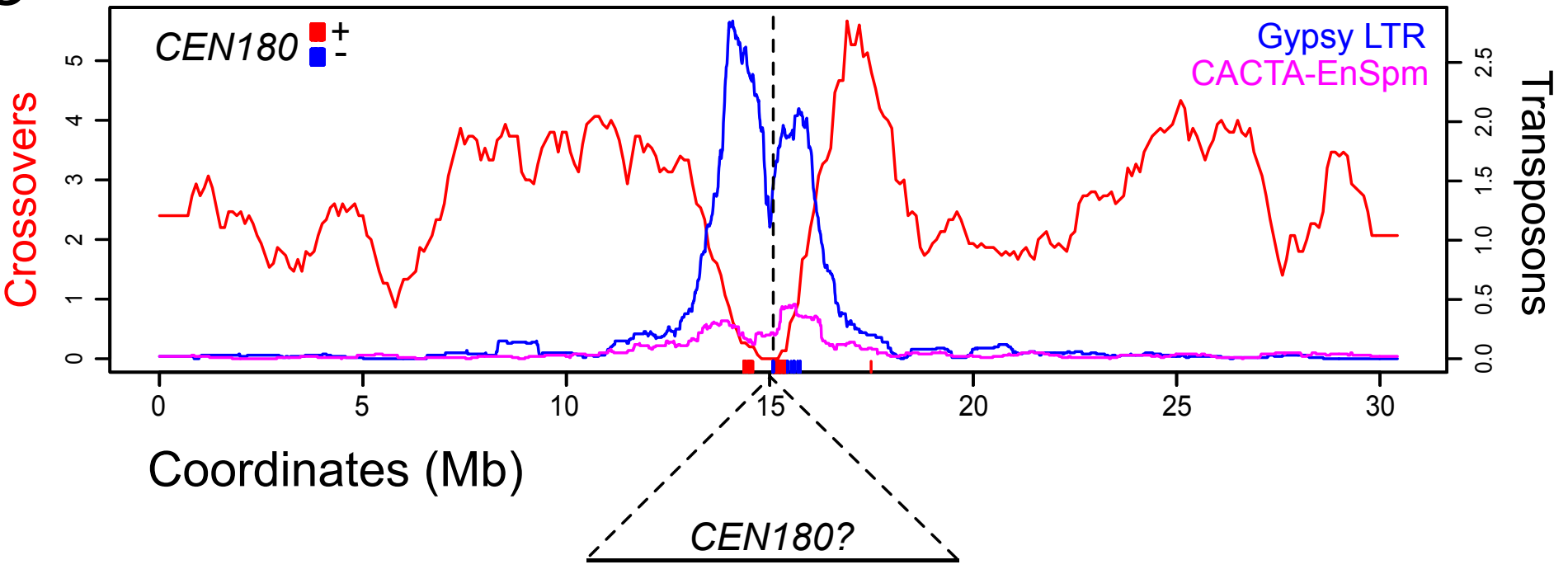


A

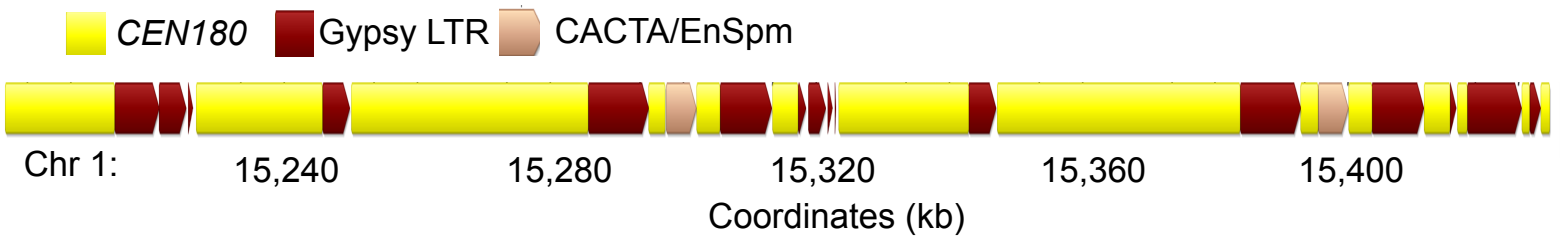

B
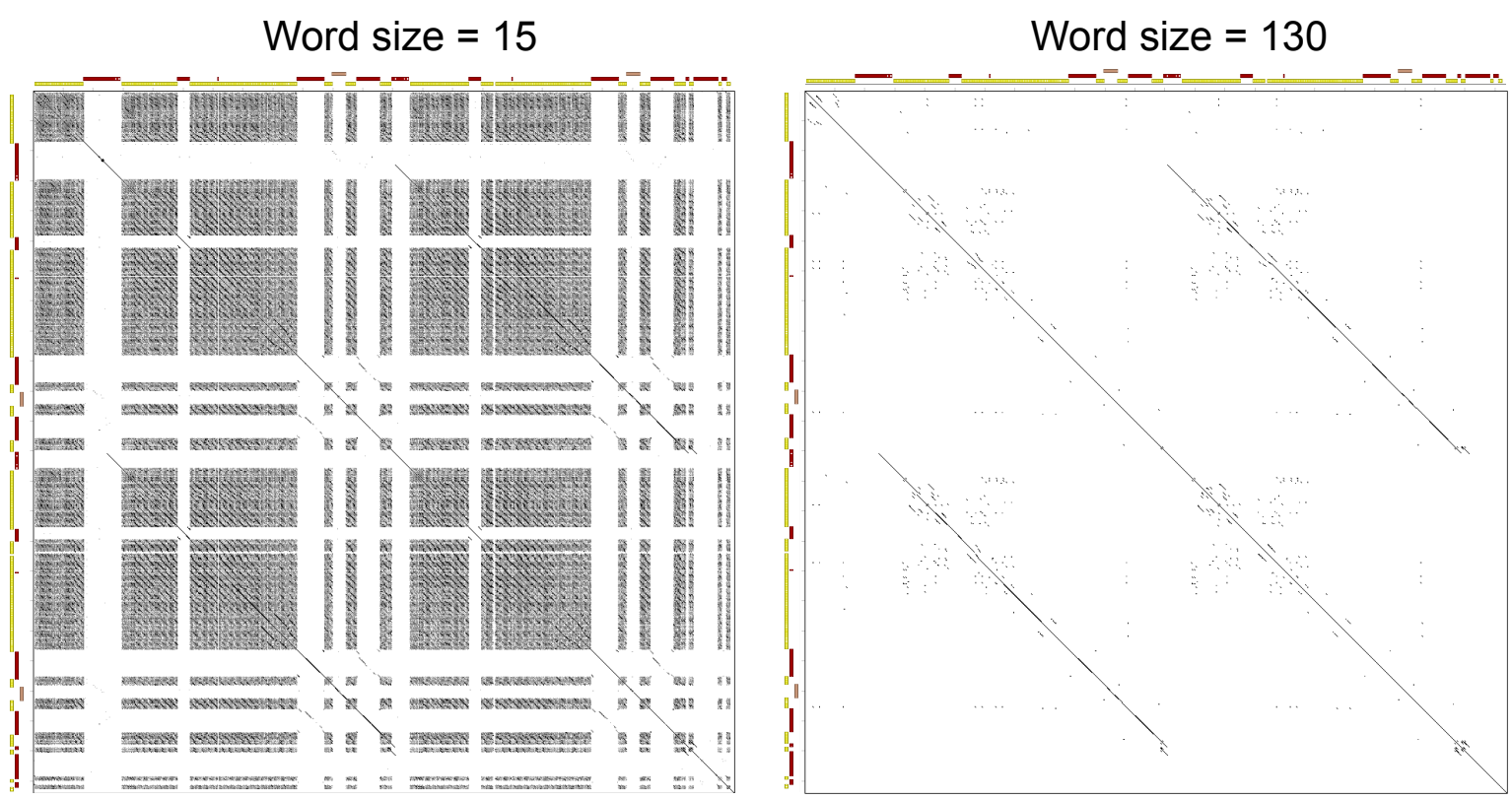